\title{
La reforma laboral implementada durante el segundo gobierno de Alfonso López Pumarejo
}

\author{
The labor reform implemented \\ during the second government of \\ Alfonso López Pumarejo \\ Da reforma laboral implementada \\ durante o segundo governo de \\ Alfonso Lopez Pumarejo
}

Fecha de recepción: 23 de agosto de 2015

Óliver Mora Toscano*

Concepto de evaluación: 29 de octubre de 2015

Fecha de aprobación: 9 de diciembre de 2015

PhD en Economía. Economista y Administrador Público. Docente asistente de tiempo completo de la Universidad Pedagógica y Tecnológica de Colombia UPTC. Tunja, Colombia. Correo electrónico: olivermoratoscano@gmail.com 


\section{Resumen}

En este artículo se estudian los elementos más relevantes de la reforma laboral propuesta y puesta en práctica por el presidente Alfonso López Pumarejo durante su segunda gestión de Gobierno. La reforma fue implementada fundamentalmente a través de la Ley $6^{\text {a }}$ de 1945 . Los elementos más relevantes de la misma fueron la institucionalización y regulación de los movimientos obreros para que contribuyesen de esta forma a la estabilidad del crecimiento económico y el desarrollo empresarial pretendido en ese momento por el Estado colombiano, así como el reconocimiento de un conjunto de reivindicaciones y derechos a los trabajadores urbanos, que hicieron de esta reforma la más avanzada en Colombia en términos sociales durante el siglo XX.

Palabras clave: reforma laboral, movimientos sociales, sindicatos.

Clasificación JEL: J88, O17, J50.

\section{Abstract}

This article studies the most relevant elements of the labor reform proposed and implemented by President Alfonso López Pumarejo during his second term of government. The reform was implemented fundamenta1ly across the Law $6^{\text {th }}$ of 1945 . The most relevant elements of this reform were the institutionalization and regulation of the labor movements that contribute in this way to the stability of the economic growth and the business development claimed in this moment for the Colombian State, as well as the recognition of a set of claims and rights to urban workers, that made of this reform the most advanced in Colombia in social terms during the $20^{\text {th }}$ century.

Keywords: labor reform, social movements, unions. 


\section{Resumo}

Neste artigo, os elementos mais importantes da proposta de reforma laboral implementado pelo presidente Alfonso Lopez Pumarejo durante seu segundo mandato de governo. A reforma foi executada principalmente através da Lei 6 da 1945. Os elementos mais significativos do que fosse a institucionalização e regulação dos movimentos de trabalhadores a contribuir desta forma para a estabilidade do crescimento económico e de desenvolvimento de negócios destinado no momento pelo Estado colombiano e do reconhecimento de um conjunto de reivindicações e direitos para os trabalhadores urbanos, que fizeram esta reforma mais avançada na Colômbia em termos sociais no século XX.

Palavras-chave: reforma laboral, movimentos sociais, sindicatos. 


\section{INTRODUCCIÓN}

Este artículo estudia los elementos más relevantes de la Ley $6^{\mathrm{a}}$ de 1945 , mediante la cual se implementó una reforma laboral durante la segunda administración de Alfonso López Pumarejo. Los principales propósitos de esta legislación fueron, en primer lugar, la regulación e institucionalización de los sindicatos y los movimientos obreros y, segundo, el reconocimiento de un conjunto de reivindicaciones y derechos de los trabajadores que habían sido reclamados por estos desde finales de los años veinte.

La gestión de Gobierno de López Pumarejo es considerada como una de las más destacadas e importantes del siglo XX en Colombia. El conjunto de políticas y reformas ejecutadas durante sus dos administraciones abrieron el camino para grandes transformaciones en el papel del Estado, la economía, la industria, la tenencia de la tierra, la educación pública, las relaciones laborales, entre otros aspectos políticos, económicos y sociales.

López Pumarejo gobernó Colombia durante dos períodos. El primero, entre 1934 y 1938, y el segundo, entre 1942 y 1945 . De los dos períodos, el más relevante por el conjunto de transformaciones propuestas y realizadas fue el primero. En efecto, durante este período fueron realizadas importantes reformas como la constitucional y agraria de 1936 y la reforma educativa. Durante su segundo período enfrentó grandes limitaciones que le impidieron continuar a profundidad su labor reformista. Entre estas limitaciones se destacan la férrea oposición de importantes sectores de la élite económica y política del momento, así como las restricciones económicas externas existentes ante el desarrollo de la Segunda Guerra Mundial y 
la disminución de los precios del café, principal producto de exportación de Colombia en aquella época.

Estas resistencias crearon un ambiente de ingobernabilidad, que se acentuó con el intento de golpe de Estado acontecido en 1944. Este contexto de conflicto conllevó la renuncia de López en 1945, faltando todavía un año para la finalización formal de su segundo período presidencial. A pesar de estas dificultades, durante su segunda administración fue posible la aprobación de la reforma laboral, reforma que en varios aspectos ha sido una de las más avanzadas socialmente en la historia colombiana y que será objeto de análisis en este artículo.

Para comprender el contexto y el alcance de la reforma se analizan primero las características de la política laboral aplicada durante el primer Gobierno de López Pumarejo. En cierto sentido, la Ley $6^{a}$ es resultado de esa política cuyo objetivo principal fue la consecución de una estabilidad en las relaciones obrero-patronales, que permitiese fomentar el crecimiento y la modernización económica.

Posteriormente es examinada la legislación laboral propuesta por el Gobierno lopista y aprobada por el Congreso. Este análisis comprende la presentación del contexto general existente entre 1942 y 1945 y el estudio de los aspectos centrales de la Ley $6^{\mathrm{a}}$. Por último, a partir de los aspectos planteados en este subcapítulo se efectúa un balance general de la reforma.

LA POLÍTICA LABORAL DURANTE EL PRIMER GOBIERNO DE ALFONSO LÓPEZ PUMAREJO

En general, la segunda república liberal entre 1930 y 1946 respaldó la creación y organización de sindicatos pero bajo unos parámetros que permitieran su regulación por parte del Estado. El Gobierno que más auspició esta política fue el de Alfonso López Pumarejo.

Las razones de esta concepción eran políticas y económicas. Desde lo político, Alfonso López y el liberalismo buscaban el apoyo de los trabajadores urbanos en su batalla electoral por el poder del Estado con el Partido Conservador. Igualmente existía el objetivo de respaldar un aumento y consolidación de la influencia de la burguesía industrial y disminuir así el poder y preponderancia que habían adquirido los terratenientes (Moncayo \& Rojas, 1979, p. 57). El predominio de los grandes propietarios de la tierra en cierta forma constituía un obstáculo a la intencionalidad de modernización y de reformas. Respecto a los aspectos económicos, la visión del Partido Liberal en general y del presidente López en particular, era que la organización sindical y sus movimientos reivindicativos favorecían el 
mejoramiento de la capacidad adquisitiva de estos trabajadores. Este mejoramiento estimulaba la ampliación del consumo y del mercado interno, creando así las condiciones para el crecimiento de la industria y la producción nacional.

Los esfuerzos por la institucionalización de los sindicatos comienzan desde el Gobierno de Enrique Olaya Herrera con la expedición de la Ley 83 de 1931 sobre organización sindical. Esta norma constituyó un mecanismo a través del cual el Estado buscaba establecer la regulación y vigilancia de los movimientos reivindicativos. Esta regulación de los sindicatos era establecida a través de la potestad del Estado para reconocer o no la personería jurídica de estos y en la capacidad de solicitar la disolución de alguna organización sindical en aquellos casos en donde sus acciones estuviesen por fuera de la ley (art. 19). También en la competencia para imponer multas cuando sean realizadas huelgas consideradas como ilegales (art. 22) y, finalmente, en la posibilidad de disolución de aquellas organizaciones que participaran activamente en política (art. 23).

Durante la primera administración de López Pumarejo no fue posible la implementación de una reforma laboral.
Existieron proyectos sobre asuntos específicos, algunos aprobados, otros no. En 1937 fue promulgada la Ley 40 , la cual reglamentó el apoyo estatal a los congresos obreros. Al final de este primer Gobierno, en 1938, fue creado el Ministerio de Trabajo. Los asuntos laborales hasta ese momento eran responsabilidad del Ministerio de Industrias.

A pesar de no haber conseguido la aprobación de una reforma, la política laboral de López entre 1934 y 1938 fue muy activa. Esta se caracterizó en lo fundamental por el estímulo a la formación de sindicatos y la activa intervención gubernamental como mediador en los conflictos laborales. En general, el presidente respaldó en esos conflictos las reivindicaciones de los trabajadores, situación que le permitió adquirir una gran popularidad entre estos.

El Partido Comunista Colombiano (PCC) inicialmente se opuso al Gobierno lopista. ${ }^{1}$ Sin embargo, el aumento de la popularidad del presidente entre los trabajadores hizo insostenible esa oposición. Esta agrupación se había opuesto al anterior Gobierno de Olaya Herrera e incluso observaba en López a un agente más de la "oligarquía" colombiana. Sin embargo, durante el transcurso del primer año de

En general, el Partido Comunista no aceptaba la mediación del Gobierno en las huelgas. Esta actitud cambia a partir del respaldo que esta organización entrega al presidente López. 
Gobierno esta apreciación fue paulatinamente mudando hasta ofrecer su apoyo político al presidente. Esta decisión estuvo motivada principalmente por la creciente influencia de López sobre los sectores populares, el temor a la radicalización de la oposición de los grupos de derecha a la política reformista del Gobierno (y que esto derivara en un Gobierno represivo de carácter fascista) y las directrices provenientes desde la Unión Soviética de apoyar a los sectores progresistas de la burguesía, ante la coyuntura política internacional de ese momento ${ }^{2}$.

El apoyo político a López por parte de los comunistas se expresó en la ejecución desde noviembre de 1935 , y por iniciativa de estos, de la estrategia política del "Frente Popular" (Partido Comunista Colombiano, 1960, pp. 35$36)^{3}$. Este no constituyó un Gobierno formal, sino que sirvió de instrumento de apoyo a las dos administraciones de Alfonso López, a diferencia de otras experiencias como la de Francia,
Chile o España. El presidente aceptó implícitamente este apoyo, mas nunca concedió al PCC un poder real en las decisiones de su Gobierno (Archila, 1991, p. 291). Otras organizaciones de izquierda adhirieron al Frente Popular como Vanguardia Socialista y el Partido Agrario Nacional (PAN) que lideraba las movilizaciones campesinas en la región del Sumapaz, en los departamentos de Cundinamarca y Tolima. Los trabajadores urbanos y sus sindicatos también ofrecieron su apoyo. La alianza del lopismo con los sectores populares fue respaldada dentro del Liberalismo solo por el ala progresista o de izquierda de este partido ${ }^{4}$.

El término "Frente Popular" era utilizado principalmente por el Partido Comunista, no tanto por los integrantes de los sindicatos. Mucho menos era usado formalmente por parte del Gobierno. Para López, esta expresión era un "fantasma" que solo estaba en la imaginación de sus opositores (Pécaut, 2001, p. 288). De esta forma López intentó

\footnotetext{
Estas directrices de apoyar gobiernos burgueses progresistas fue establecida a partir del VII Congreso de la Internacional Comunista celebrado en agosto de 1935.

3 La conformación del Frente Popular significó una mudanza en la estrategia que hasta ese momento había aplicado el Partido Comunista. Este cambio implicó, por lo tanto, el congelamiento, al menos temporal, de la táctica de la insurrección y la revolución popular (Archila, 1991, p. 291).

4 Dentro del Partido Liberal colombiano de la época existían dos tendencias políticas. Una era la que asumía una posición moderada respecto a la intencionalidad reformadora del primer Gobierno lopista, y que en esa época era comúnmente conocida como la "derecha" liberal. Entre sus principales representantes estaban, entre otros, Eduardo Santos (propietario del periódico más importante del país, "El Tiempo", y líder de este sector del liberalismo), Juan Lozano y Lozano y Luis Cano. La otra tendencia estaba constituida por aquellos congresistas que expresaban una posición más radical frente a las reformas propuestas por López, y eran partidarios de una mayor profundización de las mismas en términos de los avances sociales, la limitación del poder de la Iglesia Católica, la intervención del Estado en la economía y la sociedad y la redistribución de la tierra en el campo. En ese momento eran conocidos como el sector progresista o de "izquierda" del liberalismo y entre sus principales representantes estaban Diego Montaña Cuéllar y Gerardo Molina, quienes en los años siguientes abandonan el liberalismo y se convierten en dos de las más destacadas figuras históricas de la izquierda colombiana.
} 
minimizar la existencia y el alcance de este término para evitar así una mayor confrontación con los sectores de la oposición. Sin embargo, esto no significaba la inexistencia de una alianza política entre el Gobierno, los sectores progresistas del liberalismo, los sindicatos, los socialistas y el Partido Comunista. Ella efectivamente existió y constituyó una base de apoyo importante al proyecto político lopista ${ }^{5}$.

Una de las consecuencias del respaldo de los comunistas a López fue la posibilidad del establecimiento de la unidad entre los distintos sindicatos. Entre comienzos de la década de los treinta y mediados de los cuarenta del siglo XX existían en Colombia dos grandes tendencias en el sindicalismo, aquellas organizaciones influenciadas por el liberalismo y los sindicatos controlados por el Partido Comunista. Dentro del Partido Liberal se destacaba la influencia de la Unión Nacional Izquierdista Revolucionaria (UNIR) dirigida por el líder político Jorge Eliécer Gaitán.

Como existían diferencias entre los comunistas y la UNIR, que recientemente se había integrado al liberalismo, ese proceso no resultó fácil. En la consecución de la unidad sindical y la superación de estas diferencias fue importante la labor desempeñada por la izquierda liberal.

La unidad del sindicalismo colombiano era importante para López, por cuanto facilitaría su regulación por parte del Estado y así mismo sería útil como forma de apoyo político a su gestión reformista. Esta apoyo era necesario ante la oposición del conservatismo, la derecha liberal, la Iglesia Católica, los terratenientes y sectores importantes del empresariado. Estos sectores observaban con desconfianza este acercamiento entre el lopismo y las organizaciones populares y de izquierda. De hecho, la derecha liberal nunca respaldó esta aproximación porque la consideraba peligrosa para la estabilidad política del país.

La unidad sindical se alcanzó efectivamente en el Segundo Congreso Obrero realizado en la ciudad de Medellín en 1936 y se expresó en el nacimiento de la Confederación Sindical de Colombia (CSC), posteriormente denominada Confederación de Trabajadores de Colombia (CTC) ${ }^{6}$. Esta unidad se manifestó más específicamente en la

\footnotetext{
5 El periódico Claridad, medio de divulgación formal del Partido Agrario Nacional (PAN), expresaba claramente el pensamiento de la izquierda colombiana de la época respecto al respaldo a López: "Las agrupaciones de izquierda han acertado al conjugar en una sola voluntad (haciendo referencia al Frente Popular) para respaldar eficazmente al gobierno democrático del Doctor Alfonso López Pumarejo" (Claridad, 1936).

6 La confederación sindical que nace en Medellín en 1936 inicialmente se denominó Confederación de Sindicatos de Colombia (CSC). Esta denominación cambia por su nombre actual, Confederación de Trabajadores de Colombia (CTC), a partir del Tercer Congreso Obrero realizado en Cali en enero de 1938. Sin embargo, ese cambio fue aprobado oficialmente solo hasta octubre de 1943 durante la realización del Quinto Congreso en Bucaramanga (Escuela Nacional Sindical, 2010, pp. 2-4).
} 
conformación del comité ejecutivo de la confederación, ocho (8) liberales, cuatro (4) comunistas, tres (3) socialistas y un (1) anarcosindicalista (Archila, 1991, p. 298). La conformación de esta central sindical adquiere un significado político y electoral importante para el presidente y en general para el Partido Liberal. Es por eso que a partir de ese momento el Gobierno comienza a apoyar financieramente la realización de congresos obreros y también mediante la presencia de alguno o algunos de sus ministros. En la declaración final de este Congreso se hace una invitación explícita a los trabajadores a apoyar al Gobierno de López Pumarejo:

Apoyo franco al gobierno nacional que preside el doctor López como contra medida a las fuerzas reaccionarias de los godos que, con una aguda ortodoxia capitalista, tratan de impedir que el trabajador sea en nuestra tierra un ciudadano con todos los derechos y no siga viviendo una vida de paria o del idiota a que lo condujeron, a través de duras épocas, viejos y pasados regímenes. (Escuela Nacional Sindical, 2010, p. 3)

El presidente no rechazó la adhesión del Partido Comunista. El respaldo político de las organizaciones populares se oficializó el $1^{\circ}$ de mayo de 1936 durante la masiva manifestación del Día del Trabajo y a la cual asistió, desde el palacio de Gobierno, el mismo López. Este acto tuvo una importante repercusión en la política nacional e intensificó la oposición de los sectores de derecha. En general, la izquierda procuraba con la adhesión al Gobierno lopista realizar una alianza política con un sector de la burguesía que ellos consideraban como progresista, con el objeto de contribuir en la modernización capitalista, la industrialización y la democratización de la sociedad, esto dentro del marco de la democracia burguesa (Pécaut, 2001, p. 282).

Como se mencionó atrás, uno de los aspectos relevantes de la política laboral durante la primera administración del presidente López fue el estímulo gubernamental a la creación y legalización de sindicatos. Efectivamente se presentó un aumento en el número de sindicatos reconocidos por el Gobierno entre 1935 y 1938. Las organizaciones sindicales legalizadas en 1935 fueron 84, 38 en 1936, 157 en 1937 y 93 en 1938. Respecto al número de trabajadores afiliados a los sindicatos, este creció de 42.678 en 1935 a 94.190 en 1941 (Urrutia, 1969, p. 199). Los sindicatos afiliados a la CTC y más importantes en la década de los treinta pertenecían a los sectores agrícola, industrial, de transportes y petrolero (Urrutia, 1969, pp. 298-303). Aun así, el sindicalismo continuaba siendo para la época "una expresión minoritaria de los trabajadores asalariados" (Archila, 1991, p. 300) ${ }^{7}$.

En 1939 la tasa de sindicalización era menos del $10 \%$ (Archila, 1991, p. 300). La CTC reunía para ese año el $40 \%$ de los sindicatos reconocidos y el $50 \%$ de la población sindicalizada (Urrutia, 1969, p. 183). 
A pesar de lo anterior, el sindicalismo de los treinta era más estable en comparación con las organizaciones obreras existentes en la década de los veinte. Igualmente tenía objetivos reivindicativos más específicos, como la jornada laboral de ocho horas y el establecimiento del salario mínimo, aunque experimentó una mayor dependencia respecto al Estado en relación con aspectos como la iniciativa de creación y organización de sindicatos.

La reacción de la Iglesia y el Partido Conservador al impulso del sindicalismo desde el Gobierno y la consecuente conformación de la CTC consistió en la creación de sindicatos confesionales católicos respaldados por los dueños de las empresas. Esta estrategia fue fomentada por la Acción Social Católica, organización patrocinada por la misma Iglesia (Archila, 1991, p. 307). Ya en 1939 se podían observar los resultados iniciales de esta estrategia. La Acción Social Católica había contribuido en la creación de un total de setenta y tres (73) sindicatos hasta ese momento y que sumaban 10.515 integrantes.

Como se mencionó, uno de los propósitos de la proximidad de López a los sindicatos era el ejercicio de una mayor regulación del Estado a las huelgas y en general a las movilizaciones obreras. Esto incentivó una injerencia gubernamental cada vez más creciente en la mediación de los conflictos entre trabajadores y patronos. La alianza conformada en ese momento entre los sindicatos y el Estado estaba sin embargo en permanente tensión entre las intenciones de radicalización de los paros existentes en sectores importantes de la base obrera y el control y regulación de los conflictos pretendida por el Gobierno (Archila, 1991, p. 303).

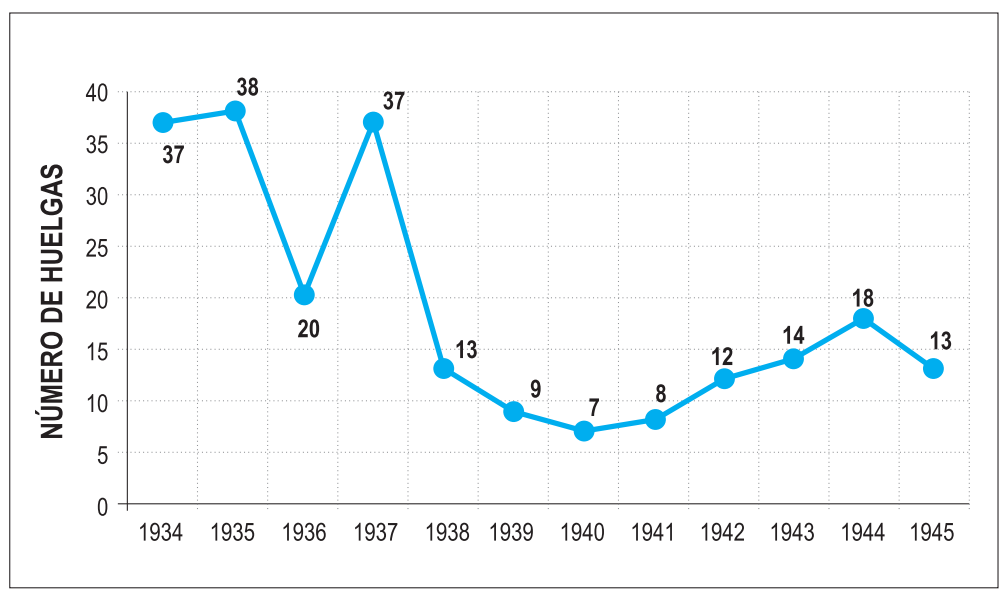

Figura 1. Número total de huelgas por año entre 1939 y 1945 Fuente: Archila (1991, p.269), Ministerio de Trabajo (1945). 
Efectivamente, a pesar de la influencia de López Pumarejo sobre los trabajadores, el Estado no ejercía una regulación completa sobre los movimientos de protesta de estos. El aumento de las huelgas en sectores en donde se suponía no podían ser realizados paros como los servicios públicos, las tomas de fábricas y el aumento en las huelgas en el sector industrial, son algunas demostraciones de esa realidad. Es así como entre 1934 y 1938 se presenta un incremento de las huelgas en relación con los años anteriores. En 1934 son 37 huelgas, en 1935 aumentan a 38, disminuyen en 1936 a 20, aumentan nuevamente a 37 el año siguiente y en 1938 se registra el menor número para el período, 13 huelgas en total (Figura 1). Este incremento en la conflictividad laboral se explica por el incentivo a la creación de sindicatos promovido por Gobierno, la mejor organización de estos y la unidad conseguida a través de la creación de la CTC y la actitud en general favorable a los intereses de los trabajadores asumida por López en la mediación de estos conflictos ${ }^{8}$.

El Gobierno hace un esfuerzo por asumir como propia la organización e institucionalización de los sindicatos con el doble objetivo de tener mejores mecanismos de regulación sobre estos y al mismo tiempo convertirlos en un instrumento de apoyo político al proyecto político lopista. La consecución de la unidad sindical y la consecuente aparición de la Confederación de Trabajadores de Colombia (CTC) son expresión de ese propósito de institucionalización del movimiento obrero por parte del Gobierno de López Pumarejo.

Los conflictos laborales más importantes acontecidos durante el primer Gobierno de López Pumarejo fueron: en 1934 los paros de los transportadores del río Magdalena (principal río del país y de gran importancia en la época para el transporte de mercancías y pasajeros), los ferrocarriles del Pacífico y los trabajadores de la zona bananera, en el norte del país. En 1935 ocurrió nuevamente una huelga en la zona bananera, además de conflictos en el Ferrocarril de La Dorada (departamento de Caldas), los trabajadores petroleros de la Tropical Oil Company en Barrancabermeja (departamento de Santander) y la intensificación en ese mismo año de los paros en el sector industrial, principalmente en Bavaria, Vidrios Fenicia y las empresas textileras de Medellín. En 1936 las huelgas afectan nuevamente las empresas más importantes del sector textil,

\footnotetext{
8 En cierto sentido, los trabajadores, principalmente urbanos, se sintieron respaldados políticamente por el Estado, aunque también existieron casos específicos en donde las autoridades gubernamentales declaraban la ilegalidad de las huelgas. A pesar de estos casos, los cuatro años de la primera administración de López, principalmente entre 1934 y finales de 1936 (hasta el inicio de la "pausa" en la continuación de las reformas impuesta a López por la oposición), constituyen el período en donde se presentó un mayor acercamiento entre los sindicatos y el Estado colombiano.
} 
Coltejer y Rosellón; al año siguiente se produjo una importante huelga realizada de nuevo por los trabajadores de las empresas transportadoras del río Magdalena. También se presentan huelgas en los servicios públicos de Medellín. En 1938 aparece una nueva protesta por parte de los trabajadores de la Tropical Oil Company, la cual concluye con un saldo trágico de tres muertos (Archila, 1991, pp. 291-298).

Además del aumento de los salarios y el mejoramiento de las condiciones de trabajo, las huelgas acontecidas entre 1934 y 1938 buscaban el reconocimiento legal de los sindicatos y el derecho a la negociación laboral. Los empresarios manifestaban su oposición a la organización en sus empresas de estos sindicatos y a su reconocimiento oficial (Pécaut, 2001, p. 249).

Dos ejemplos de la mediación del Gobierno en los conflictos laborales fueron la intervención personal del presidente en las huelgas de los trabajadores de la United Fruit Company en diciembre de 1934 y la Tropical Oil Company ocurrida un año después. En ambos conflictos el Gobierno presionó y consiguió un aumento considerable de los salarios. Este tipo de mediaciones fue frecuente durante la primera gestión de López, acciones que contribuyeron al respaldo político de los trabajadores y los sindicatos al Gobierno (Pécaut, 2001, pp. 251-252).

La disminución a trece (13) en el número de huelgas al final de la administración de López Pumarejo en 1938 sugiere un relativo éxito en el intento de control estatal de la protesta social, a través de la canalización institucional de las distintas reivindicaciones de estos movimientos ${ }^{9}$. Sin embargo, a partir de 1937, los empresarios comenzaron a presionar al Gobierno para restringir el derecho de huelga, ante el incremento de los conflictos laborales. Por esta razón es presentado un proyecto de ley en donde se precisan aquellos sectores en donde por su importancia se limita la realización o duración de las huelgas. Este era un llamado del Estado a los sindicatos a restringir el uso del paro y buscar otras alternativas para solucionar los conflictos. En el segundo Congreso Obrero realizado en la ciudad de Cali en enero de 1938, los sindicatos se oponen a ese proyecto, pero al mismo tiempo manifiestan su apoyo al Gobierno en la necesidad de restringir el uso de la huelga. Los sindicatos allí reunidos expresan que solo se apoyarían aquellas huelgas que hicieran uso de los requisitos establecidos por la ley para su realización (Urrutia, 1969, pp. 174-176).

\footnotetext{
9 Esta canalización institucional se intentó establecer mediante la implementación de las reformas sociales propuesta por López, la organización y creación de sindicatos influenciados y, en cierta medida, controlados por el Estado y la mediación que el Gobierno realizó en muchos de los conflictos de la época.
} 
La intencionalidad reformadora del presidente generó una gran polarización entre el bloque que lo apoyaba y aquel que se oponía a su Gobierno. El nivel de tensión entre estos bloques fue tan intenso que amenazó con transformarse en un conflicto de carácter civil. Este contexto de creciente enfrentamiento, junto con el fracaso electoral de aquellos sectores del liberalismo que apoyaban el proyecto político lopista en las elecciones al Congreso de abril de 1937 (el ala progresista del Partido Liberal), influyeron en la decisión del Gobierno de interrumpir la implementación de nuevas reformas. La derrota en las elecciones significó una demostración del gran poder de la oposición. La movilización de las masas urbanas impulsada por López no había logrado así derrotar la maquinaria electoral tradicional (Pécaut, 2001, p. 286).

A pesar de la "pausa" en la intencionalidad reformadora, las organizaciones populares (PCC, PAN, socialistas, sindicatos, trabajadores urbanos y población en general) deciden continuar respaldando la gestión del presidente. Con ese respaldo ellos buscaban también "preservar a cualquier precio la frágil unidad política que acababan de obtener por intermedio del gobierno" (Pécaut, 2001, p. 283).

Los industriales en un principio parecieran haber apoyado la gestión del presidente y también la política laboral y el acercamiento a los sindicatos. Ellos requerían de la organización y apoyo de los trabajadores para poder contrarrestar la influencia y poder de los terratenientes y de los sectores comerciales vinculados a ellos (Moncayo \& Rojas, 1978, p. 53). Esta fue la situación al comienzo del primer Gobierno de López.

Sin embargo, a partir de 1937 se presenta una disminución de la productividad de las industrias y una tendencia a la también reducción de la tasa de ganancia. Esta situación obliga a los empresarios de este sector a procurar un descenso en los salarios de los trabajadores (Moncayo \& Rojas, 1979, p.59). Este contexto se agrava a partir del inicio de la Segunda Guerra Mundial. Este conflicto produce el encarecimiento de las importaciones de bienes de capital y el cierre de los mercados internacionales para las exportaciones (esto acentúa la disminución salarial y el desempleo).

Ante esta realidad económica y las limitaciones del desarrollo industrial del momento, los industriales comienzan a ver como inconveniente la continuidad de un proyecto de reformas sociales que en sus inicios ellos habían apoyado. Esta es una de las razones por las cuales presionan al Gobierno lopista para detener la política reformista. En palabras de Moncayo y Rojas, "la detención del proceso se articula plenamente con los intereses de la burguesía que, forzada por las 
circunstancias, debe abandonar el impulso y auspicio de la actividad reivindicativa sindical, para no alterar las condiciones de tasa de ganancia y para no echar a pique, por ende, las condiciones ya creadas y asentadas" $(1979$, p. 60).

Desde la perspectiva de estos actores (los industriales), el presidente, además de estimular la organización de los sindicatos (organización con la que en un principio estaban de acuerdo), fue más lejos y les entregó una mayor capacidad política al aceptar la alianza entre estos y el Partido Comunista. También los industriales consideraron que las reformas realizadas, a pesar de no ser radicales, iban más allá de lo tolerable. Por esta razón, a partir de 1937 los industriales consideraron que la intencionalidad reformadora de López, con la cual estaban de acuerdo en un comienzo, adquirió unas características que ellos no compartían $\mathrm{y}$ es por eso que paulatinamente retiraron su respaldo hasta formar parte de la oposición junto con otros sectores de la sociedad (los terratenientes, el Partido Conservador, la Iglesia Católica y la derecha liberal). A partir de ese momento los industriales iniciaron una batalla en cada una de sus empresas contra aquellos sindicatos que se iban creando por iniciativa del mismo Estado (Pécaut, 2001, p. 283).

Ellos manifestaban de esta forma su desacuerdo con la implementación de las reformas sociales propuestas por el Gobierno lopista. Cada vez que este presentaba un proyecto de ley laboral que incluía algún tipo de beneficio a los trabajadores (como la obligación en el pago de cesantías o la participación de los trabajadores en las utilidades de las empresas), iniciaban de inmediato una campaña para presionar al Gobierno a retirar esas propuestas o que fuesen estas rechazadas por el Congreso (Pécaut, 2001, p. 283). Esta es la razón fundamental por la cual fue imposible para el presidente lograr la aprobación de cualquier reforma en el campo laboral durante su primera administración.

Esta actitud de la burguesía industrial implica también un rechazo a la existencia y consolidación del sindicalismo que se generaría a través de la promulgación de las leyes sociales. Para el conjunto de los empresarios y los terratenientes era inaceptable la existencia de los sindicatos y también su fortalecimiento político. La oposición observaba desde su perspectiva que el Gobierno, bajo el pretexto de controlar a las organizaciones populares y a la izquierda en general, estaba consiguiendo todo lo contrario, es decir, alimentando y fortaleciendo el "peligro comunista". En síntesis, uno de los mayores temores de las élites del momento eran los riesgos de la "politización de las masas populares" que supuestamente estaba estimulando el presidente (Pécaut, 2001, p. 285). 
Con la derrota del lopismo en las elecciones parlamentarias de 1937, el sector de derecha del liberalismo asume nuevamente el control del partido. Al asumir este control, la derecha liberal niega la posibilidad de cualquier intervención del sindicalismo en política. Este sector del liberalismo, que triunfa con Eduardo Santos en las elecciones presidenciales de 1938, concibe los sindicatos y en general las organizaciones populares como un simple instrumento electoral que serviría para derrotar electoralmente al conservatismo y, por lo tanto, les exige el abandono de cualquier pretensión de constituir una fuerza política específica. ${ }^{10}$

El papel de las organizaciones populares se ve limitado entonces a aportar sus votos en los procesos electorales a favor del liberalismo y a controlar la proliferación de las huelgas entre sus afiliados. Las organizaciones populares aceptan esta nueva coyuntura política y continúan expresando, aun en estas condiciones, su respaldo al Gobierno y en general al liberalismo. Ante estas circunstancias, no existe entonces la posibilidad de construcción de un movimiento obrero independiente.

Durante el Congreso de la CTC en enero de 1938 los trabajadores aceptan la limitación de las huelgas sugerida por el Gobierno. Esta misma decisión es asumida por el Partido Comunista. La razón es el temor de que estas huelgas sean utilizadas como pretexto por parte de la oposición para destruir definitivamente el acercamiento político alcanzado entre las organizaciones populares y el Partido Liberal en general y el Gobierno lopista en particular. A partir de ese momento cualquier sindicato afiliado debe obtener permiso de la Confederación para poder realizar un paro.

El deseo de la izquierda era por lo tanto mantener esa alianza implícita que existía con el Partido Liberal y la burguesía nacional que fue fortalecida durante la primera administración de López, así gran parte de esta burguesía estuviese en contra de ella. Aunque los trabajadores y sus distintas formas de expresión eran conscientes de las restricciones que imponía el ambiente político existente, consideraban sin embargo que el respaldo al

\footnotetext{
10 Esta pretensión de la derecha liberal se puede apreciar en una parte de la declaración del Directorio Nacional del partido del 31 de enero de 1938. En ese momento el liberalismo ya es controlado nuevamente por ese sector, después del triunfo en las elecciones a Congreso de 1937: "El partido, en armonía con sus programas, estimula la sindicalización de todos los gremios de trabajadores y apoya el sindicato como instrumento legal de reivindicación o de cooperación en el proceso de trabajo, sin intervención en las luchas electorales y sin finalidades políticas. (...) La Dirección considera que, aceptada por el partido la sindicalización apolítica, no se deben tolerar las pretensiones de elementos netamente políticos encaminadas a dirigir o controlar los sindicatos. Así mismo estima que no puede ser diferente a los sindicalizados liberales la organización democrática de Colombia. (...) El liberalismo no tiene ninguna afinidad ideológica con el comunismo y condena la lucha de clases y todo instrumento político que actúe fuera del sistema republicano..." (El Tiempo, 1938).
} 
Gobierno constituía "la única expresión política posible" para mantener la movilización popular a favor de la democracia y en contra del fascismo (Pécaut, 2001, p. 292). Es por esta razón que la izquierda en su conjunto (Partido Comunista, socialistas y CTC) deciden apoyar a Eduardo Santos en las elecciones presidenciales de 1938 para "defender la democracia" de la amenaza supuestamente fascista del Partido Conservador ${ }^{11}$. Al hacer más énfasis en la defensa de la democracia, ante la coyuntura del momento, estos sectores dan más importancia a las alianzas políticas que a las transformaciones sociales. En general, esta alianza con la izquierda y los sindicatos permite al liberalismo apropiarse del voto urbano en su enfrentamiento electoral con el conservatismo.

\section{LA IMPLEMENTACIÓN DE UNA LEGISLACIÓN LABO- RAL. CONTEXTO GENERAL}

La formulación y aprobación de una reforma laboral solo es posible durante la segunda administración de López Pumarejo. Esta intenta resolver los conflictos existentes en las relaciones entre obreros y patronos, y crear así un ambiente que permita estimular el crecimiento, la modernización económica y el desarrollo industrial.
El estudio de la misma comprende, en primer lugar, la presentación del contexto existente entre 1942 y 1945 respecto a las movilizaciones de los trabajadores, los sindicatos, su respaldo al Gobierno y en general el ambiente político predominante en ese momento. Estos aspectos, junto con la política laboral desarrollada durante el primer Gobierno lopista, influyeron en la concepción de la reforma.

Posteriormente son estudiados los elementos centrales de la Ley $6^{\text {a }}$ de 1945. Los aspectos más destacados de esta norma están relacionados con dos temas principales, los mecanismos de regulación de las movilizaciones obreras y los sindicatos, y el reconocimiento de un conjunto de derechos de los trabajadores inexistentes hasta ese momento en la legislación.

Durante el Gobierno de Eduardo Santos (1938-1942) se intenta provocar una división del movimiento sindical, el cual había logrado su unidad a través de la CTC durante el Gobierno anterior de López. Esta división tiene como propósito excluir a los comunistas y socialistas de las directivas de los sindicatos. Es así como el Gobierno santista promueve la inasistencia de los sindicalistas liberales al cuarto Congreso de la CTC realizado en

\footnotetext{
1 Pécaut considera que la concepción del Partido Comunista, los socialistas, los sindicatos y la misma izquierda liberal de considerar a Laureano Gómez y al Partido Conservador como fascistas era completamente equivocada (2001, p.293). El conservatismo era para la época una organización política de derecha y con unos estrechos vínculos con la Iglesia Católica y sin ninguna proximidad con las ideas políticas de Hitler o Mussolini.
} 
Barranquilla en 1940. Igualmente fue expedido el Decreto 1485 de 1942 mediante el cual se limita aún más el derecho a la huelga y se establece prácticamente una conciliación forzosa en los conflictos laborales, conciliación que beneficia los intereses de los empresarios. Las restricciones impuestas se reflejan en la disminución del número promedio de paros realizados. Durante la primera administración de López ese promedio fue de 29; ya en la administración Santos la media se reduce a 9 huelgas (Ministro de Trabajo, 1939, 1940, 1941, 1942).

Después de estas tentativas de división, los sindicatos se unifican nuevamente en 1941 para adherir a la campaña presidencial de López y respaldar posteriormente su segundo Gobierno. Durante su segunda gestión, el difícil contexto político creado por la oposición junto con las dificultades económicas surgidas como consecuencia de la Segunda Guerra Mundial, hicieron que el presidente asumiese una actitud política más moderada respecto a la continuidad de las reformas. Aun así, los obreros y trabajadores urbanos y sus sindicatos, el Partido Comunista, los socialistas y en general las organizaciones políticas de izquierda continuaron expresando su apoyo al Gobierno. El presidente, una vez elegido en 1942, estaba en una situación compleja por cuanto debía satisfacer los intereses de los trabajadores quienes manifestaban su permanente respaldo y, al mismo tiempo, no provocar la reacción en contra de empresarios, terratenientes y comerciantes, quienes dudaban de su capacidad de contener la movilización de las organizaciones populares.

En este período también se presentó una menor injerencia del Estado en la mediación de los conflictos laborales y en el apoyo a los trabajadores en sus reivindicaciones ${ }^{12}$. Sin embargo, existió una continuidad en la política de fomento a la conformación de sindicatos y su legalización. En 1942 fueron legalizadas treinta y ocho (38) organizaciones sindicales, setenta y nueve (79) en 1943, ciento ochenta (180) en el siguiente año y cuatrocientos y cincuenta y tres (453) en 1945 (Moncayo \& Rojas, 1979, p. 63; Urrutia, 1969, p. 63). En 1946, cuando López ya había renunciado, el número de sindicatos reconocidos oficialmente disminuyó a ciento dieciséis (116). Solo en diciembre de 1942 , a seis meses del inicio del segundo Gobierno, el total de sindicatos aumentó de 742 a 809 organizaciones con 102.023 afiliados (Archila, 1991, p. 333), con una importante

\footnotetext{
12 En general, el Gobierno asumió una posición intermedia entre los intereses de los trabajadores y de los empresarios en los conflictos laborales acontecidos entre 1942 y 1945 . Esta posición es diferente a la actitud asumida entre 1934 y 1938. En ese momento existió una tendencia en el Gobierno a favorecer las reivindicaciones de los primeros.
} 
participación de los trabajadores de la industria. En 1945 surge la sindicalización de los trabajadores gubernamentales a través de la conformación de la Federación Colombiana de Trabajadores del Estado, organización que desempeñará un importante papel dentro del sindicalismo en los años posteriores. También fueron creados durante este lapso sindicatos en la rama judicial, en los bancos y en el sector educativo.

Durante el segundo Gobierno de López, el Partido Comunista reactivó nuevamente la estrategia del Frente Popular. Mediante esta, al mismo tiempo que respaldaba al presidente, presionaba también la realización de reformas sociales y económicas. Ante el contexto político internacional de la época, este partido decidió aplazar temporalmente su proyecto de revolución y apoyar al Gobierno. En 1941 esa organización cambió su nombre por el de Partido Socialista Democrático (Archila, 1991, p. 341).

En ese momento el Gobierno de López aceptaba el apoyo recibido de las organizaciones políticas populares, mas prefería mantener una prudente distancia para no exacerbar aún más el ya difícil contexto político. Sin embargo, este acercamiento, específicamente con los comunistas, permitió el establecimiento por primera vez de relaciones diplomáticas con la Unión Soviética.
Durante 1942 fueron realizadas doce (12) huelgas, en el siguiente año acontecieron catorce (14), dieciocho (18) en 1944 y trece (13) en 1945 (Figura 1). Las principales huelgas ocurrieron en los ferrocarriles, el transporte fluvial por el río Magdalena, las minas de oro de Segovia en el departamento de Antioquia, el transporte terrestre, entre otras (Archila, 1991, pp. 335-338).

El menor número de huelgas durante el segundo Gobierno del presidente López en relación con el primero podría ser explicado por varios factores. Entre estos se destacan las limitaciones del comercio exterior de la época ante las dificultades creadas por la Segunda Guerra Mundial, el apoyo entre los trabajadores a la causa de los aliados en este conflicto y principalmente por la adhesión política de estos a la figura personal del presidente. Una expresión de este respaldo es la aceptación por parte de los sindicatos de la reglamentación y limitación del derecho de huelga. Esta limitación incluye la prohibición de los paros en los servicios públicos. Esta tendencia oficial de tratar de restringir las huelgas se explica por la fuerte presión de los industriales, mas también por la necesidad de controlar los paros acontecidos en sectores estratégicos como el transporte. Estos paros sucedieron en 1942 y 1943, fueron incentivados por los mismos empresarios y constituyeron en aquel momento una estrategia de la oposición para intentar desestabilizar al Gobierno. De hecho, el 
ambiente de confrontación política fue intenso en esos años y tuvo su máxima expresión en el intento de golpe de Estado de 1944.

No obstante el acuerdo alcanzado sobre la restricción de la huelga, cuando el Gobierno presentó un proyecto de ley en 1943 para reglamentar esa decisión, los trabajadores manifestaron su oposición. Esta oposición se dirigió no tanto al presidente sino al ministro de Trabajo de la época. Al final, este proyecto fue retirado temporalmente y el ministro se vio forzado a renunciar por petición del mismo López. La situación descrita refleja la permanente tensión existente en las organizaciones sindicales respecto a dos posiciones aparentemente contrarias. Por un lado, las presiones de la base obrera por no relajar la realización de movimientos de protesta en casos específicos de conflictos laborales. Y por el otro, el compromiso de sindicatos como la CTC de apoyar políticamente al presidente e intentar limitar las huelgas con el objeto de no introducir un factor adicional de inestabilidad en un momento político crítico para el Gobierno.

Uno de los factores que explica el ataque permanente de la oposición de derecha al presidente fue su relación de relativa cercanía con las organizaciones sindicales y populares y en general con los sectores de izquierda como el Partido Comunista. Este "ataque a López era en el fondo una ofensiva contra esos sectores populares" (Archila, 1991, p. 339-340). En el caso específico de los empresarios, estos no compartían el apoyo político de las organizaciones populares y los sindicatos al Gobierno, y tampoco las medidas económicas restrictivas implementadas ante las dificultades generadas por la Segunda Guerra Mundial.

La presión de los industriales, así como la concepción del Estado liberal de lograr la institucionalización de los movimientos reivindicativos y de los sindicatos a través de la regulación estatal, explican uno de los aspectos más destacados de la reforma laboral de 1944, el del establecimiento de más mecanismos de regulación al derecho de huel$\mathrm{ga}^{13}$. De esta forma, los empresarios conseguían una limitación de las luchas reivindicativas que pudiesen conducir a aumentos reales de la remuneración de los trabajadores y, por lo tanto, afectasen su tasa de ganancia en un contexto de dificultades económicas (Moncayo \& Rojas, 1979, p. 340).

A pesar de no ser un Gobierno obrero, en ese momento el único sector que respaldaba la gestión del presidente era

\footnotetext{
13 Los mayores mecanismos de regulación a la actividad sindical fueron implementados inclusive desde finales del primer Gobierno de López a través del Decreto 2342 de 1938 sobre vigilancia de los sindicatos, y la Ley 96 de ese mismo año, que crea y organiza el Ministerio de Trabajo, Higiene y Previsión Social.
} 
precisamente la izquierda, es decir, los trabajadores urbanos y sus sindicatos, el sector progresista del liberalismo, el Partido Comunista y los socialistas. Esta situación era paradójicamente diferente a la que existió durante la década de los veinte. "Si en esa época la subversión que amenazaba al Estado provenía de la izquierda, para mediados de los años cuarenta la izquierda era el único soporte que le quedaba al Estado contra la cada vez más agresiva oposición derechista" (Archila, 1991, p. 340).

Cuando en 1944 Alfonso López presenta su primera renuncia a la presidencia, los sindicatos y los comunistas convocaron el 15 de mayo un paro cívico nacional para impedir que el Senado aceptara esta renuncia. Este paro recibió un importante apoyo de los sectores populares y efectivamente consiguió su propósito y la renuncia del presidente no fue aceptada (El Espectador, 1944). Este mismo respaldo expresado en masivas manifestaciones populares evitó el éxito del intento de golpe de Estado de julio de 1944.

En un intento por apaciguar la oposición, López intentó buscar nuevos aliados y es en este contexto que aparece la aprobación y promulgación de la Ley 100 de 1944, la cual fue favorable a los grandes propietarios agrícolas. Sin embargo, esta legislación fue también una forma de negociación con el Congreso para que este aprobase tanto la reforma laboral de 1944 como la reforma constitucional de 1945.

La reforma laboral expresó la concepción de López sobre la regulación estatal de los sindicatos y los conflictos obreros-patronales. Para él, esta regulación desempeñaba un papel fundamental en la prosperidad de las empresas y de la economía nacional. Las siguientes palabras del presidente publicadas en el periódico liberal "El Espectador" expresaban esa idea:

. . . la oposición ha pretendido que soy el inventor de un monstruoso instrumento de lucha de clases. Los sindicatos que existían estaban previstos, ordenados, estimulados y protegidos por la ley. Pero no estaban en la ley. Procedían irregular y revolucionariamente. (. . .) El gobierno liberal logró que los sindicatos actuaran dentro de la ley, se sometieran a ella y que los obreros y campesinos se convirtieran desde entonces en celosos vigilantes de la ejecución cabal de las leyes de trabajo existentes, en vez de ser como eran sus adversarios. (. . .) El haber convencido a los patronos y obreros, a los representantes del capital y el trabajo, de que podían discutir directamente sus conflictos, y que no eran en forma alguna los agentes de dos clases sociales en lucha, sino los interesados comunes en la prosperidad de sus empresas, no fue ciertamente fácil (...). (El Espectador, 1942) 
Como se observa en la anterior cita, uno de los propósitos de la acción gubernamental era solucionar y estabilizar las relaciones entre trabajadores y empresarios, para contribuir así a la existencia de un ambiente favorable al crecimiento y la modernización económica. En este contexto resulta fundamental traducir estos objetivos en la legislación existente. De ahí surge entonces la necesidad de implementar una reforma laboral.

Es así como posterior al intento de golpe de 1944, López decide presentar al Congreso un proyecto de legislación sobre ese tema. En ese momento existió tanto en el Senado como en la Cámara un ambiente de solidaridad un poco más favorable hacia el Gobierno, principalmente dentro del liberalismo. Esta coyuntura fue aprovechada por el presidente para conseguir la aprobación de sus dos últimas reformas, además de la laboral aquí analizada, la reforma constitucional de 1945. En cualquier caso esa relativa favorabilidad temporal no fue suficiente para amainar el contexto de confrontación existente. Es por eso, y ante la amenaza de convertirse esta confrontación en prácticamente una guerra civil, que López decide renunciar definitivamente ante el Congreso a mediados de $1945^{14}$.

\section{LA IMPLEMENTACIÓN DE UNA LEGISLACIÓN LABO- RAL. LOS ELEMENTOS CEN- TRALES DE LA REFORMA}

Después del intento de golpe de Estado del 10 de julio de 1944, el Gobierno, respaldado en las facultades extraordinarias originadas en el régimen de estado de excepción, promulga dos decretos laborales de carácter tempo$\mathrm{ral}^{15}$, el 1778 y el 2350 de 1944 . El Decreto 1778 prohíbe temporalmente las huelgas por considerarlas incompatibles con la declaratoria del estado de excepción y establece en su lugar el arbitramiento obligatorio. Ya el Decreto 2350 adelanta un conjunto de reglamentaciones sobre las luchas reivindicativas para dar así una respuesta a las presiones de los trabajadores.

Sobre el estado de excepción y la prohibición temporal de las huelgas, prohibición que va a ser eliminada posteriormente con la promulgación de la reforma laboral, López justifica su realización por la difícil situación política y económica del momento. Específicamente él dice:

El gobierno procede con la certidumbre de que si se levantara el estado de sitio antes de que existan disposiciones que regulen de una manera

\footnotetext{
14 De hecho, desde el intento de golpe de Estado en julio de 1944 la izquierda y los sindicatos asumieron una actitud más beligerante en defensa del gobierno y comenzaron a aparecer enfrentamientos en distintas ciudades entre estos y los grupos de la oposición.

15 Estos dos decretos estaban vigentes solo durante el transcurso de tiempo que durara el estado de excepción.
} 
ordenada, prudente y eficaz las relaciones entre el capital y el trabajo, y sin que las autoridades administrativas hayan podido contener el encarecimiento constante de los artículos de primera necesidad, se desataría una agitación social sin precedentes, una ola de huelgas y desórdenes que se ha aplazado por las medidas provisionales indicadas (. . .) (El Tiempo, 1944).

Según palabras del mismo presidente, la nueva legislación laboral que estaba proponiendo el Gobierno en ese momento tenía como propósito:

Ofrecer al país un estatuto que solucione conflictos ya existentes o en potencia, muchos de los cuales vienen de años atrás amargando y complicando inútilmente, por deficiencia de las leyes, las relaciones de los patronos y los subalternos. Las leyes existentes son insuficientes, son contradictorias, son ineficaces para prevenir tales conflictos y no los encauzan hacia desenlaces de justicia sino con lentitud exasperante (El Tiempo, 1944).

Como puede ser observado en estas palabras, uno de los principales propósitos del Gobierno con la reforma laboral fue completar la institucionalización de los conflictos obreros mediante el establecimiento de unos mecanismos de solución, a través de la mediación y la regulación gubernamental.

El Decreto 2350 era de carácter temporal, porque fue expedido con fundamento en las facultades del estado de excepción. Por lo tanto, tenía un tiempo límite de vigencia. Es por esto que el contenido de esta norma fue presentado como proyecto de Ley al Congreso. Una vez surtido el trámite de discusión, este proyecto fue aprobado como la Ley $6^{a}$ de 1945 , norma que estableció la reforma laboral. Los principales objetivos de esta reforma fueron el desarrollo de unos mecanismos de regulación e institucionalización de los sindicatos y las movilizaciones obreras y el reconocimiento de un conjunto de reivindicaciones y derechos de los trabajadores que habían sido reclamados por estos desde finales de los años veinte.

Al revisar las actas de discusión contenidas en varios de los Anales del Senado de 1944, se observa que fueron introducidas varias modificaciones al proyecto original presentado por el Gobierno. Estas modificaciones limitan el alcance de los derechos laborales establecidos originalmente en la propuesta gubernamental y disponen también mayores restricciones al derecho de huelga (Senado, 1944, 1945).

La Ley $6^{\text {a }}$ de 1945 institucionaliza la existencia del sindicato organizado dentro de una empresa, más conocido como sindicato de base o de empresa. Este tipo de organización sindical sería el sujeto legítimo mediante el cual los movimientos reivindicativos podrían expresar sus distintas aspiraciones. La medida pretende desestimular 
la importancia de las federaciones de sindicatos (como la CTC), trasladando la interlocución reivindicativa a las organizaciones de cada empresa en particular. De esta manera, la reforma otorga la potestad de la negociación colectiva y la dirección de las huelgas preferentemente a los sindicatos de cada empresa, en detrimento de las federaciones sindicales.

De esta forma, la reforma debilita la capacidad de acción de las agrupaciones más fuertes y dinámicas existentes en ese momento como la Federación Nacional de Trabajadores de Transporte Fluvial, Marítimo, Portuario y Aéreo (Fedenal) y la confederación única, la CTC. La norma también permitió la injerencia de los trabajadores no sindicalizados en la declaratoria de una huelga y amplió los sectores considerados como "servicio público".

En este sentido, las federaciones no pueden presentar pliegos de peticiones si existen sindicatos de base o de empresa. El Estado quería evitar con esto la politización de la lucha obrera, politización que era más posible a nivel de estas federaciones sindicales que a nivel de cada sindicato particular. Existe así el intento de excluir a estas (a las federaciones) de las negociaciones durante el desarrollo de los conflictos laborales

El proyecto de ley presentado por el Gobierno lopista (Decreto 2350 de 1944) establecía el fuero sindical para los fundadores y los miembros de la junta directiva de los sindicatos. Ya en el proceso de discusión en el Congreso el alcance de esta iniciativa, que favorecería el fortalecimiento de la organización sindical, fue restringido. La ley finalmente aprobada reconoce este fuero, pero estableció un sistema mediante el cual este podría ser desconocido. Este sistema se convirtió posteriormente en un instrumento que utilizarían los empresarios para poder excluir así de los movimientos reivindicativos a los dirigentes más combativos (Moncayo \& Rojas, 1979, p. 63).

En la reforma laboral implementada mediante la Ley $6^{\mathrm{a}}$ se prohíbe el paralelismo sindical, es decir, la existencia de más de un sindicato dentro de una misma empresa. Esta medida quería evitar una práctica común en la época, que consistía en la formación por parte de los empresarios de sindicatos paralelos favorables a sus intereses. Estas organizaciones paralelas debilitaban la lucha reivindicativa de los trabajadores afiliados al sindicato original que promovía las huelgas y las movilizaciones (Giraldo, 1994, p. 100). La reforma estipula que, en caso de existir más de un sindicato en la empresa, subsiste aquel que reúna un mayor número de afiliados.

En el proyecto original se señalaba que la declaración de la huelga era potestad de los sindicatos, independientemente de la proporción de trabajadores de la empresa que reuniese. En el 
texto de la ley definitivamente aprobada esta potestad es restringida. En ella se establece que si el sindicato no tiene afiliados al menos la mitad del conjunto de todos los trabajadores de la empresa, la huelga solo sería legítima si era declarada por la mitad más uno del total de trabajadores de la firma.

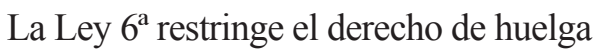
en aquellas organizaciones que provean o presten un servicio público. De acuerdo con el artículo cincuenta (50) de la norma, son considerados como servicios públicos, además de la administración pública y el órgano judicial, "las empresas de transporte por tierra, agua y aire y las de acueducto, energía eléctrica y telecomunicaciones (...) la higiene pública, el aseo de las poblaciones y las instituciones de asistencia pública y beneficencia como hospitales, clínicas, asilos y hospicios". También "las plantas de leche, las plazas de mercado y mataderos pertenecientes a entidades públicas". Estas últimas no estaban contempladas en el proyecto gubernamental original y fueron agregadas durante la discusión del proyecto de ley en el Congreso.

El alcance de la restricción del derecho de huelga en las empresas de servicio público es explicado en el artículo cincuenta y uno (51). En este se indica que estas entidades "no podrán suspender ni paralizar labores sino mediante permiso del gobierno, o dándole aviso a éste con seis (6) meses de antelación...". Cuando se presente alguna huelga en una organización definida por la norma como de "servicio público", así sea esta de carácter privado, "el gobierno queda autorizado para asumir su dirección y tomar todas las providencia necesarias para restablecer los servicios suspendidos y garantizar su mantenimiento" (artículo 52). Esto significa que en caso de ser aprobada y realizada una huelga en una entidad prestadora de un servicio público, el Estado podría hasta sustituir a los administradores privados (cuando se trate de una empresa no estatal) y desarrollar todas aquellas medidas necesarias para reanudar la continuidad del servicio interrumpido por la protesta. Esta potestad, otorgada al Estado por la Ley 6 ${ }^{\text {a }}$, prácticamente implica la prohibición de la huelga en cualquier entidad que preste un servicio público, sea esta de naturaleza estatal o privada (Moncayo \& Rojas, 1979, p. 73).

Además de los aspectos relacionados con la regulación del sindicalismo, la Ley $6^{\mathrm{a}}$ de 1945 introduce por primera vez en la legislación colombiana varios elementos de avanzada sobre la reglamentación del trabajo, los derechos de los trabajadores y las obligaciones sociales de los patronos. Estos aspectos significaron en la época un importante avance en la normatividad laboral existente.

Estos elementos comienzan en el parágrafo 1 del artículo tercero en donde se fija que "las horas de trabajo no podrán exceder de ocho (8) horas al día 
ni de cuarenta y ocho a la semana (. . .)". Sin embargo, para el caso de las actividades ganaderas señala que esas horas máximas serán de nueve (9) horas diarias o cincuenta y cuatro (54) semanales. La limitación establecida no aplica para las actividades agrícolas ni para el servicio doméstico.

En el parágrafo 3 del artículo mencionado se reglamenta el pago de horas extras. Así, "cuando el trabajo se realice entre las ocho y las doce de la noche, deberá ser remunerado con un veinticinco por ciento $(25 \%)$ sobre el valor del trabajo diurno; y cuando se realice entre las doce de la noche y las cuatro de la mañana siguiente, será remunerado con un cincuenta por ciento (50\%) sobre el mismo valor".

En el artículo cuarto se indica que el Gobierno podrá establecer por medio de decretos los salarios mínimos para cualquier región económica o cualquier actividad profesional, industrial, comercial, ganadera o agrícola de conformidad con el costo de vida, las modalidades de trabajo, los sistemas de remuneración o la capacidad económica de las empresas. Estos decretos podrán ser promulgados previo concepto de comisiones en donde estén representados en igual número los patronos y los trabajadores.

La Ley $6^{\mathrm{a}}$ en el artículo 5 prohíbe las diferencias salariales fundamentadas por razones de "sexo, edad, religión, opinión política o actividades sindicales". También prohíbe a los patronos "imponer a los trabajadores obligación alguna de carácter religioso, político o electoral" o impedir el ejercicio del derecho de sufragio. En el parágrafo 1 de ese mismo artículo la norma prohíbe igualmente el pago de salarios en especie. La reforma establece también la obligación de remunerar los domingos y los días festivos al trabajador.

En relación con las obligaciones sociales de los patronos, la reforma señala que estos deben garantizar a los trabajadores la asistencia médica, farmacéutica, quirúrgica y hospitalaria en caso de enfermedad o accidentes en el lugar de trabajo. Cuando la enfermedad sea no profesional y por fuera del ambiente de trabajo, las empresas están en la obligación de pagar un auxilio hasta por ciento ochenta días de incapacidad comprobada equivalente al $75 \%$ del salario durante los primeros noventa días de ausencia y a la mitad para el resto de días (artículo 17, literal e). La norma ordena igualmente el pago de indemnizaciones por enfermedad profesional $o$ accidentes durante la jornada laboral, la incapacidad laboral hasta por ciento ochenta días y el derecho de vacaciones anuales remuneradas por quince días (artículo 12).

En el artículo catorce (14) la ley establece el derecho de jubilación vitalicia a todos aquellos trabajadores que cumplan cincuenta (50) años de edad después de veinte (20) años de servicio 
continuos o discontinuos. También dispone la pensión de invalidez para el "empleado u obrero que haya perdido su capacidad de trabajo para toda ocupación u oficio" (artículo 17, literal c). Igualmente en el artículo doce (12) señala a las empresas la obligación del pago por cada año de trabajo en el caso de los trabajadores permanentes, y por cada tres (3) años para los no permanentes, de un auxilio monetario destinado a cubrir las necesidades del empleado cuando este quede cesante (pago de cesantías).

La Ley $6^{\text {a }}$ reconoció el contrato de trabajo como entidad jurídica autónoma y el predominio legal del contrato escrito. Igualmente favoreció los mecanismos de negociación de las peticiones de los trabajadores. Respecto a la organización institucional de la seguridad social, la norma autoriza en el artículo dieciocho (18) la creación de la Caja de Previsión Social de los Empleados y Obreros Nacionales. Esta institución será creada formalmente en 1946 con el nombre del Instituto Colombiano de Seguros Sociales.

La reforma laboral crea la Jurisdicción Especial del Trabajo. Esta jurisdicción tiene como propósito decidir sobre las "controversias que suscite, directa o indirectamente, la ejecución del contrato de trabajo entre patronos y asalariados, entre asalariados solamente, entre las asociaciones profesionales de patronos y las de asalariados, o entre los asalariados y sus asociaciones profesionales (. . .)" (artículo 58). Ella será ejercida de forma permanente a través de los Juzgados del Trabajo, los Tribunales seccionales de Trabajo y la Corte Suprema del Trabajo como instancia final de decisión (artículo 59). La creación de esta jurisdicción constituye un esfuerzo adicional del Estado por institucionalizar la solución pacífica de los conflictos laborales.

Aunque la reforma laboral estableció mecanismos de control estatal a la actividad sindical, los empresarios en general no estuvieron de acuerdo con aquellas medidas que beneficiaban a los trabajadores. Ellos argumentaban que estas medidas significarían un aumento de los costos laborales y por lo tanto una disminución de sus ganancias. Esta situación determinó una mayor oposición de estos empresarios y por lo tanto la intensificación de la presión sobre el Gobierno (Giraldo, 1994, p.101). Este contexto de permanente y creciente conflicto condujo a la renuncia definitiva del presidente en julio de 1945.

Como se mencionó atrás, la aprobación de la reforma laboral en el Congreso fue posible por varios factores. El ambiente de solidaridad con el Gobierno entre la mayoría liberal después del intento de golpe, la presión de los sindicatos y como forma de contraprestación por la aceptación gubernamental de la Ley 100 de 1944 sobre temas agrarios. En el Congreso de esa 
época existía una importante representación de los grandes propietarios de la tierra y de ahí el sentido de la contraprestación citada.

Aquellos aspectos de la reforma que favorecieron a los trabajadores podrían interpretarse como una manera del presidente de corresponder al permanente apoyo a su Gobierno por parte de estos y sus sindicatos (Molina, 1986, p. 170). Este respaldo, junto con el de la izquierda liberal y el del Partido Comunista, fue fundamental para detener el intento de golpe de Estado de julio de 1944. Sin embargo, también es cierto que dentro de una concepción de sociedad moderna como la que quería implementar López para el caso colombiano, la concesión de derechos laborales y el establecimiento de las obligaciones sociales de los patronos era importante dentro de la misma. Por lo tanto, la reforma laboral, al igual que el resto de reformas implementadas por López, son en parte consecuencia de la intencionalidad de modernización de la sociedad colombiana expresada desde su primera administración entre 1934 y 1938.

CONCLUSIONES: EL BALANCE DE LA POLÍTICA Y REFORMA LABORAL IMPLEMENTADA POR LÓPEZ PUMAREJO

La política y la reforma laboral aplicada durante las dos gestiones de Gobierno de Alfonso López Pumarejo tuvieron como principal objetivo la modernización de las relaciones entre trabajadores y patronos, así como la creación de una institucionalidad laboral que permitiera el establecimiento de unos mecanismos de regulación estatal a los sindicatos y los movimientos obreros.

De esta forma el Estado pretendía encauzar la protesta de los trabajadores por el camino de la institucionalidad, queriendo evitar así el enfrentamiento y la polarización. El propósito era contribuir con un ambiente de estabilidad laboral que favoreciera el crecimiento económico, el desarrollo y la modernización de la economía y la industrialización, pilares de la intencionalidad reformadora del presidente. Desde la perspectiva gubernamental, "la misión del sindicato es propiciar un ambiente de entendimiento con las empresas, por lo mismo de cooperación para lograr así un efectivo desarrollo industrial en beneficio de la economía colombiana" (Ministro de Trabajo, 1945, p. 382).

Igualmente pretendía contener el ambiente de protesta y permanente conflictividad existente entre los trabajadores durante la década de los veinte. Precisamente el temor a una radicalización del acercamiento entre sectores de izquierda, sindicatos y Estado condujo a importantes sectores de la élite económica y política del momento a intentar romper con esa proximidad presente en el Gobierno lopista (Archila, 1991, p. 361). 
La modernización de las relaciones laborales, además de la institucionalización de las movilizaciones obreras, también implicó el reconocimiento de un conjunto de derechos de los trabajadores y el establecimiento de unas obligaciones sociales a los patronos. Esos derechos hasta ese momento habían sido negados por los distintos gobiernos, situación que había generado el surgimiento de violentas protestas en distintas regiones del país.

El presidente buscó crear mecanismos de negociación y resolución de conflictos entre los obreros y los patronos. Desde la perspectiva gubernamental, la creciente productividad industrial observada desde mediados de los treinta posibilitaría un aumento de los salarios reales (Kalmanovitz, 2003 , p. 359). Este aumento estimularía un incremento del consumo interno que favorecería el crecimiento de la producción industrial. La consecución de estos propósitos permitiría en general un mejoramiento en las relaciones laborales en las empresas y la no radicalización de los conflictos dentro de las organizaciones.

López buscaba en los trabajadores un apoyo a su proyecto político de modernización de la economía y la sociedad colombiana, para poder enfrentar así la oposición de sectores como los terratenientes, el Partido Conservador y la Iglesia Católica. Uno de los instrumentos utilizados para canalizar ese respaldo era el estímulo estatal a la movilización de la población en las ciudades y la creación de sindicatos. La creación controlada de organizaciones sindicales sirvió también de instrumento de regulación de los movimientos obreros y sociales.

Los industriales en un principio consideraron útil la alianza entre el Estado y los sindicatos. Sin embargo, a partir de 1937 las limitaciones del desarrollo industrial que generaron un estancamiento de la productividad y la tasa de ganancia, junto con el temor de una radicalización de esa alianza ante la presencia de los comunistas, hicieron a este sector retirar su apoyo a esta cercanía entre el Gobierno lopista y la izquierda.

En general, los gobiernos de la segunda república liberal, principalmente los dos del presidente López, consiguieron una mayor regulación de los sindicatos y las protestas obreras respecto al régimen conservador existente hasta 1930. Sin embargo, esa tutela no era completa y absoluta. Por esta razón, a pesar de la existencia de un mutuo respaldo entre el Gobierno lopista y los sindicatos y los trabajadores urbanos, esto no implicó la desaparición de la contradicción social y por lo tanto de las huelgas como mecanismos de presión.

Durante su segunda administración, el presidente López intentó mantener un complejo equilibrio entre las demandas de los trabajadores y los intereses 
de los empresarios. Dado el conflictivo contexto político y las dificultades económicas del momento, el Gobierno no podía asumir un respaldo claro a los trabajadores, como aconteció de manera general durante la primera gestión entre 1934 y 1938. A pesar de esta realidad, la izquierda en general, Partido Comunista, socialistas, sindicatos y la izquierda liberal, jamás retiraron su respaldo político a López Pumarejo. De hecho, fue el único sector que continuaba apoyando el presidente al momento de su renuncia definitiva.

La concepción de la política laboral de Alfonso López se expresó en la reforma implementada a través de la Ley

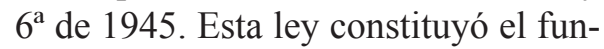
damento del primer Código Laboral. En ella existían elementos favorables a los trabajadores como el reconocimiento de un conjunto de derechos, el establecimiento de la contratación colectiva y la protección sindical. Sin embargo, también intentaba reforzar la tutela y regulación del Estado sobre los sindicatos. De esta forma limitaba aún más el derecho de huelga. Igualmente favorecía el desarrollo del sindicalismo de base o de empresa en lugar de los sindicatos del sector industrial y las confederaciones sindicales (Archila, 1991, p. 347).

Al igual que aconteció con la reforma agraria, López adopta en la reforma laboral una posición intermedia entre los intereses de los trabajadores y de los empresarios. Satisfizo los intereses de estos últimos al establecer mayores mecanismos de vigilancia estatal a los movimientos reivindicativos y a la declaración y realización de huelgas. Y también satisfizo a los trabajadores al conceder un conjunto de derechos y prerrogativas inexistentes hasta ese momento y que ellos estaban solicitando desde varios años atrás. Estas prerrogativas contempladas en la reforma laboral constituyeron un avance importante en la legislación laboral colombiana.

Entre 1934 y 1945 la clase obrera estaba todavía en un proceso de construcción de su identidad. La atracción y simpatía que generaba entre los trabajadores urbanos el discurso y la intencionalidad reformadora del presidente López "dejó una imborrable marca en la clase obrera colombiana" (Archila, 1991, p. 309). Esta clase social encontró en el Estado liberal un respaldo para hacer sentir sus reivindicaciones. La creciente polarización existente en ese momento influyó en el respaldo de los trabajadores y en general de la izquierda a la gestión de los dos gobiernos de López Pumarejo.

A pesar del aumento de los mecanismos de regulación estatal a la actividad sindical, la Ley $6^{a}$ de 1945 es reconocida hoy en día por los mismos sindicatos como "un acuerdo histórico" de los trabajadores con el Gobierno de López Pumarejo, mediante el cual el sindicalismo logró "reunir y asegurar en un texto con fuerza de ley 
las reivindicaciones que los obreros habían planteado y logrado mediante sus luchas de más de veinte años" (Escuela Nacional Sindical, 2010, p. $5)$. Es por esto que "el primer gobierno de Alfonso López será recordado por generaciones obreras como el más favorable para la clase" (Archila,
1991, p. 297). Incluso considerando sus limitaciones, observada desde una perspectiva histórica, la reforma implementada durante la segunda administración lopista constituye la legislación laboral más progresista y avanzada socialmente en la historia de Colombia.

\section{REFERENCIAS}

Archila, M. (1991). Cultura e identidad obrera: Colombia 1910-1945. Bogotá: Cinep.

Claridad (1936, 30 de sep.). Bogotá, Colombia.

Congreso de la República de Colombia (1931, junio). Ley 83 de 1931, sobre organización sindical. Bogotá: Imprenta Nacional.

Congreso de la República de Colombia (1945). Ley $6^{a}$ de 1945, por la cual se dictan algunas disposiciones sobre convenciones de trabajo, asociaciones profesionales, conflictos colectivos y jurisdicción especial de trabajo. Bogotá: Imprenta Nacional.

El Espectador (1942, 7 de abr.). Bogotá, Colombia.

El Espectador (1944, 15 de mayo). Bogotá, Colombia.

El Espectador (1944, 16 de mayo). Bogotá, Colombia.

El Tiempo (1938, 1 de feb.). Bogotá, Colombia.

El Tiempo (1944, 1 de oct.). Bogotá, Colombia.

Escuela Nacional Sindical (2010). Crónica histórica de la CTC entre 1935 y 1980. Bogotá: Escuela Nacional Sindical.

Giraldo, C. (1994). Estado y hacienda pública en Colombia 1934-1990. Bogotá: Contraloría General de la República.

Kalmanovitz, S. (2003). Economía y nación: una breve historia de Colombia (2 ${ }^{\mathrm{a}}$ ed.). Bogotá: Norma.

Ministro de Trabajo (1939). Memoria del ministro de Trabajo al Congreso Nacional de 1939. Bogotá: Imprenta Nacional. 
Ministro de Trabajo (1940). Memoria del ministro de Trabajo al Congreso Nacional de 1940. Bogotá: Imprenta Nacional.

Ministro de Trabajo (1941). Memoria del ministro de Trabajo al Congreso Nacional de 1941. Bogotá: Imprenta Nacional.

Ministro de Trabajo (1942). Memoria del ministro de Trabajo al Congreso Nacional de 1942. Bogotá: Imprenta Nacional.

Ministro de Trabajo (1943). Memoria del ministro de Trabajo al Congreso Nacional de 1943. Bogotá: Imprenta Nacional.

Ministro de Trabajo (1944). Memoria del ministro de Trabajo al Congreso Nacional de 1944. Bogotá: Imprenta Nacional.

Ministro de Trabajo (1945). Memoria del ministro de Trabajo al Congreso Nacional de 1945. Bogotá: Imprenta Nacional.

Molina, G. (1986). Las ideas liberales en Colombia. De 1935 a la iniciación del Frente Nacional. ( $7^{\mathrm{a}}$ ed.). Bogotá: Tercer Mundo.

Moncayo, V. M. \& Rojas, F. (1979). Luchas obreras y política laboral en Colombia. Medellín: Lealon.

Partido Comunista Colombiano (1960). Treinta años de lucha del Partido Comunista colombiano Bogotá: Ediciones Paz y Socialismo.

Pécaut, D. (2001). Orden y violencia. Evolución sociopolítica de Colombia entre 1930 y 1953. Bogotá: Norma.

Presidente de la República de Colombia (1944). Decreto 1778 de 1944, sobre el derecho de huelga. Bogotá: Imprenta Nacional.

Presidente de la República de Colombia (1944). Decreto 2350 de 1944, por el cual se dictan algunas disposiciones de trabajo, asociaciones profesionales y conflictos colectivos. Bogotá: Imprenta Nacional.

Senado de la República de Colombia (1944, 11 de feb.). Anales del Senado, serie 3, No 109. Bogotá: Imprenta Nacional.

Senado de la República de Colombia (1944, 2 de nov.). Anales del Senado, serie 1, No 5. Bogotá: Imprenta Nacional.

Senado de la República de Colombia (1944, 18 de dic.). Anales del Senado, serie 1, No 43. Bogotá: Imprenta Nacional. 
Senado de la República de Colombia (1945, 14 de feb.). Anales del Senado, serie 1, No 52. Bogotá: Imprenta Nacional.

Senado de la República de Colombia (1945, 23 de jul.). Anales del Senado, serie 1, No 1. Bogotá: Imprenta Nacional.

Urrutia, M. (1969). The development of the Colombian labor movement. New Haven: Yale University Press. 